\title{
Test yourself question: polyarticular pain and swelling
}

\author{
Dyan V. Flores ${ }^{1}$
}

Published online: 27 October 2016

(C) ISS 2016

\section{Question:}

A 12-year-old girl from the Philippines with seven months' history of polyarticular pain and swelling (Figs 1,2 and 3).

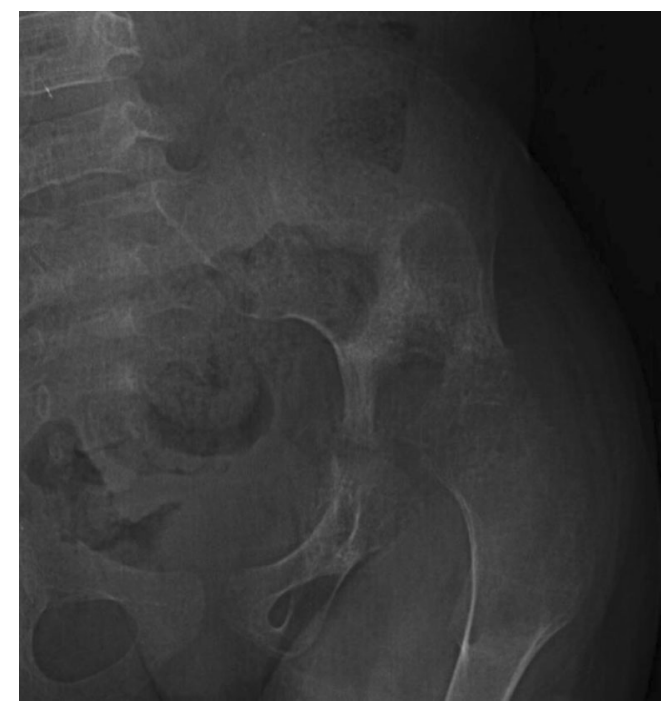

Fig. 1 Oblique radiograph of the hip

The diagnosis can be found at doi: 10.1007/s00256-016-2521-5

Dyan V. Flores

dyanflores@yahoo.com

1 Department of Radiology, Makati Medical Center, \#2 Amorsolo Street, Legaspi Village, Makati City, Metro Manila, Philippines 1229 
Fig. 2 Radiographs of the right foot

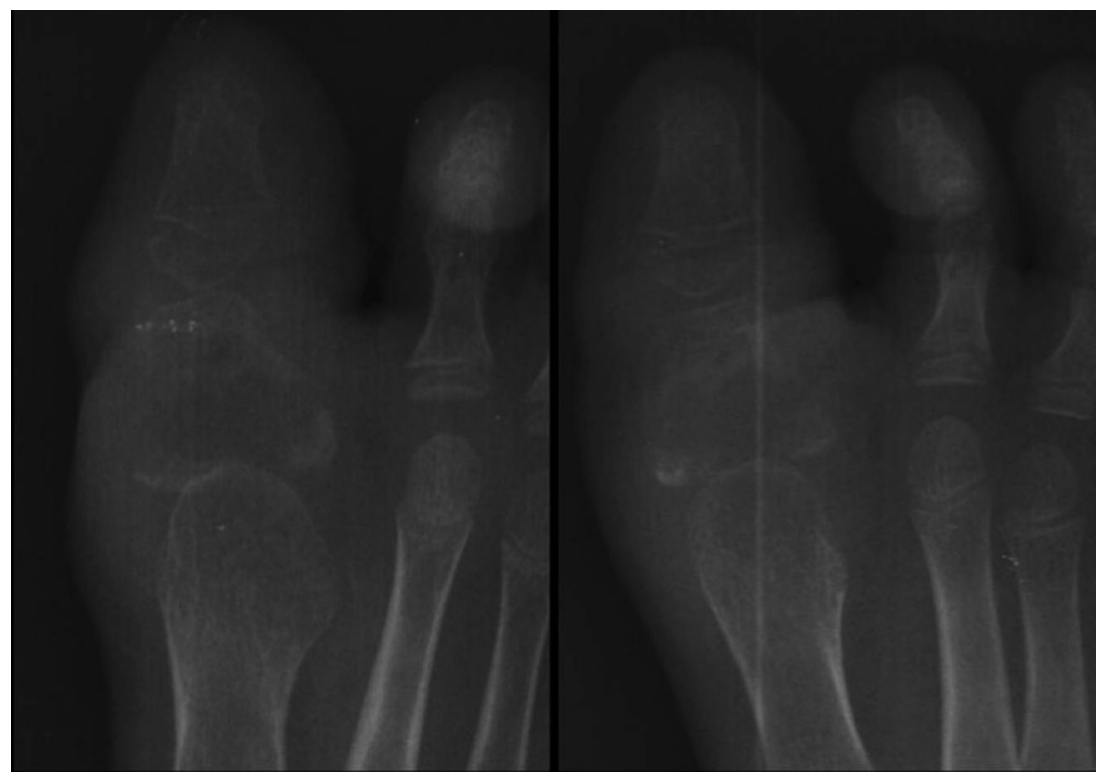

Fig. 3 Radiographs of the right hand

\section{Compliance with ethical standards}

\section{Grants received None.}

\section{Disclosures None.}

\section{Conflict of interest None.}

